\title{
Arturo de Córdova y la crisis del matrimonio burgués. De las perfectas casadas y las cenas de matrimonios (1952 y 1962)
}

\author{
Marina Díaz López \\ Instituto Cervantes, Madrid, España \\ e-mail: marina.diaz@cervantes.es
}

Submitted: 9 January 2013; Accepted: 11 March 2013

RESUMEN: Arturo de Córdova fue una estrella internacional mexicana que participó en las cinematografías de México, Argentina y España. Su carrera fue posible en un cine transnacional que logró llegar a un amplio público hispanoparlantes. En estas películas, desarrolló un personaje que fue de la estrella romántica al seductor marido que tendrá un papel importante en la sociedad de clase media, posterior a la Guerra Mundial. Actuará como un personaje de mediación entre los activos hombres de negocios y sus mujeres, que no admitirán el trabajo de casa y quedarse en un espacio privado como norma. El análisis del artículo se concentrará en dos obras teatrales que fueron llevadas al cine. Esas obras fueron escritas por dos autores españoles: Alejandro Casona en México y Alfonso de Paso en España, y fueron filmadas en estos países como Las tres perfectas casadas (1952) y Cena de matrimonios (1962). La similitud dramática en su aproximación al conflicto entre hombres y mujeres permite presentar la visión crítica elaborada contra las convenciones que daban estructura al matrimonio en esta sociedad. El hecho de que De Córdova jugara un papel protagonista en estas obras apunta a la cultura hispana compartida acerca de las cuestiones de género.

PALABRAS CLAVE: Alejandro Casona; Alfonso Paso; cine transnacional; adaptación literaria; diferencia sexual; estrellato

Cómo citar este artículo / Citation: Díaz López, Marina (2013) "Arturo de Córdova y la crisis del matrimonio burgués. De las perfectas casadas y las cenas de matrimonios (1952 y 1962)". Culture \& History Digital Journal 2(1): e17. doi: http://dx.doi.org/10.3989/chdj.2013.017

ABSTRACT: Arturo de Córdova and the crisis of the bourgeois marriage. On the role of the married women in "Las tres perfectas casadas" and the Married Couples' Dinner in "Cena de matrimonios" (1952 and 1962).- Arturo de Córdova was an international Mexican film star that managed to participate in Mexico, Argentina and Spain cinemas. His career was possible in a transnational cinema that achieved to reach to a wide Spanish speaking audience. In these films, he developed a character that went from the romantic male star to the mature seducer that will have an important role in the post-war middleclass society. He will act as a medium character between active businessman and their wives that will not admit the daily housework and be kept in a private sphere as norm. The analysis will be focussed on two plays that were adapted to the cinema. These plays were written by two Spanish authors; Alejandro Casona in Mexico and Alfonso Paso in Spain, and they were shot in these countries as Las tres perfectas casadas (1952) and Cena de matrimonios (1962). The dramatic similarity in their approach to the conflict between men and women allow us to present the critical view elaborated against the conventions that gave structure to marriage in this society. The fact that De Córdova played the main role points out the Hispanic shared culture about genre matters.

KEYWORDS: Alejandro Casona; Alfonso Paso; Transnational Cinema; Literary Adaptation; Sexual Difference; Stardom

Copyright: (C) 2013 CSIC. This is an open-access article distributed under the terms of the Creative Commons Attribution-Non Commercial (by-nc) Spain 3.0 License. 
A Patxi J. Larrañaga

"Nire buruaz mintzatzen naiz, naizelako munduaren neurria"

Gabriel Aresti, Munduaren Neurria

Aun sin haber participado en la Segunda Guerra Mundial de manera directa, todos los países latinoamericanos, y también España, resultan afectados por las consecuencias históricas de la misma. Más allá de las implicaciones políticas que tuvo el bando en el que se alineó o con el que se congració cada país, es indudable el horizonte de refundación que para la sociedad occidental supuso una paz sobrevenida sobre la pérdida de unos valores, y el auge de otros, determinados por el capitalismo y su modelo de vida. Aunque estas frases puedan sonar a conocidas, la cultura de la guerra fría impondrá un modelo de consumo, donde el cine tendrá un papel primordial (Sassoon, 2006: 1229-1256). En las películas producidas en este periodo, y en la circulación de sus temas, géneros y protagonistas, se puede encontrar un buen esquema para entender las mentalidades en liza de este nuevo espacio social. Esto es especialmente interesante para las mujeres, espectadoras y trabajadoras que han visto resituado, su lugar en la sociedad tras la guerra (Bock, 2001: 267-269). El cine será un foro de debate para la formulación de otras pautas de comportamiento respecto a los roles sociales, y también para la construcción de imaginarios más complejos en el debate de la diferencia sexual. Este espacio es crucial para la transformación de mentalidades y, sobre todo, para la cultura femenina, pues las mujeres son las espectadoras privilegiadas y asiduas en el consumo del cine. ${ }^{1}$

En este artículo se pretende abordar la posibilidad de encontrar en el cine la ejecución del debate sobre la diferencia sexual y la construcción dialéctica que esta confrontación está asumiendo dentro de la revolución que, poco a poco, trastoca la tradicional separación de los espacios públicos y privados, así como las competencias que hombres y mujeres tienen en la sociedad. El cine comercial asumirá este debate para fortalecer su visibilidad haciendo explícitas las aporías, las dificultades y la re-elaboración del patriarcado que sufre la crisis de la masculinidad monolítica y ortodoxa previa. Y del mismo modo, será un foro que también comanda la construcción de una feminidad afirmativa y dispuesta a pensarse desde la legitimidad de su deseo de ser, y de realizarse en este nuevo contexto rompiendo con los modelos previos en los que todavía está envuelta como género.

Para ello se utilizará como objeto de estudio al actor mexicano Arturo de Córdova. Estrella en el ámbito de cine en español (pues rueda en México, Argentina, Venezuela y España), su persona cinematográfica encarnará un interesante personaje de mediación sobre los conflictos entre hombres y mujeres, a lo largo de una serie de películas que se pueden agrupar en un ciclo genérico reconocible en el cine del momento. Su carrera internacional y la construcción específica de su estrellato permitirán realizar un análisis sugerente en torno a este periodo de crisis de valores y de construcción de género. Su participación en distintas cinematografías de habla hispana alienta la idea de estudiar la forma de la negociación en la que la clase media-alta busca su identidad en una esfera que es absolutamente internacional y reconocible. Se podría decir que este espacio asociado a las clases medias, de clara mentalidad burguesa, tiene una definición ambigua en lo nacional y en su responsabilidad en el modelo político y social de la posguerra, por lo que el cine en el que aparece conecta con las elaboraciones culturales que tratan de asumir las consecuencias de la crisis de un modelo de vida de una clase que se considera global. En este ámbito, la introducción de estas preocupaciones en las películas se mezcla con los elementos en los que la cultura hispana ha enunciado sus propias aproximaciones para pensar el espacio social y público, siempre desde este horizonte de clase. Por tanto, en este artículo se tratará de analizar cómo las economías propias del estrellato, así como su aparición legitimada en un cine internacional en español, harán ver la negociación entre modernidad y tradición que se elabora desde los foros de reflexión burgueses y desde una óptica propiamente hispanista.

De Córdova tiene, en la década de los cincuenta, casi veinte años de trabajo a su espalda -había debutado en 1935- que le han permitido ir elaborando las distintas edades del galán, al que es fácil atribuir las derivaciones del donjuán, propias de la cultura en español. En este tránsito, hay que añadir los elementos cosmopolitas y transnacionales que su personalidad fue adquiriendo en una interesante carrera internacional, tal y como hemos indicado. Sus doce películas protagonizadas en Hollywood entre 1940 y 1947 cimientan su personalidad como galán hispano. A este periodo sigue una sólida carrera mexicana que le lleva a realizar una media de tres películas anuales. Se convierte en figura habitual en los géneros que desarrollará la época de oro de esta cinematografía, donde es fácil encontrarle en las películas de cine negro, en los melodramas burgueses y en las comedias de enredo. A fines de la década de los cuarenta viajará a Argentina donde participará en ocho películas, varias de las cuales serán coproducciones con Brasil y una con Venezuela. Así se incorpora a un cine transnacional hispano que adapta a sus autores nacionales o que re-elabora los géneros norteamericanos desde la lectura "glocal" de estas cinematografías. Esto será entre 1947 y 1955. Finalmente, recalará en España, donde también protagonizará cinco películas entre 1955 y 1962, en las que incorpora el empaque de la 
presencia del galán tardío en los correspondientes ciclos melodramáticos españoles.

\section{LA CRÓNICA FAMILIAR CONVERTIDA EN CRÍTICA SOCIAL}

Partamos, pues, del horizonte semántico que propone este galán en la década de los cincuenta. Sus personajes se han quedado en la soltería o han construido una pareja de manera, ya abierta, ya compleja, pero siempre inoperativa. En este sentido, encontraremos en su filmografía de esta época una constancia de solteros empedernidos y mujeriegos, o de profesionales liberales que descubren vástagos desconocidos, frutos siempre de la liberalidad sexual que identifica al donjuán. En estos casos, el género en el que se resuelve la trama es la comedia, que permite a su personaje acometer el futuro de su madurez con la responsabilidad de forjar una herencia de modernización en esos hijos o justificar su sacrificio "sexual" en pos de la vigorización de las nuevas generaciones. ${ }^{2}$ Estos dos perfiles de construcción de la masculinidad asumirán una crítica a su rol tradicional de ese contexto, que se presentará también como perpleja respecto a su propia condición de sujeto masculino. A partir de aquí, se desarrolla un curioso ciclo que se materializa en varias películas sintomáticas del galán maduro que también se pueden englobar en tres derivaciones subgenéricas que combinan los modelos narrativos con las posibilidades relacionadas de los distintos topoi $^{3}$ facilitados por la estrella. Este ciclo, relacionado con su presentación en el foro del espacio público como personaje problemático o neurótico, se puede vertebrar, a su vez, en tres propuestas: (1) las comedias de enredo sobre matrimonios en crisis, ${ }^{4}(2)$ las películas que se basan en su donjuanismo cosmopolita, ${ }^{5}(3)$ la sátira social, ${ }^{6}$ serie a la que se dedicará este artículo.

Entre las películas de sátira social, pertenecientes al tercer grupo, destacan dos que tienen su origen en obras teatrales de notable éxito: Las tres perfectas casadas y Cena de matrimonios. Son dos casos que dan lugar a películas de clara confección dramatúrgica, cualidad que deja elaborar con mucha mayor precisión el locus que asume la exposición del problema en torno a la diferencia sexual, y donde se da un completo predominio de la palabra para hacer palpable el conflicto, una de las mejores características del actor De Córdova. La procedencia teatral concentra la historia en cierta unidad de espacio y tiempo, que ayuda a exponer con eficacia el desencadenante que servirá como tema para evidenciar la distancia entre hombres y mujeres, y en esta operación procurará exhibirla para comprenderla. Esta exposición no puede hacerse sin ruptura. En el tránsito de la peripecia también se explica la vertiente de crítica social que implican las rupturas, las quiebras, y su asimilación. Y de ellas, la más importante es la negociación del escándalo, fenómeno clave para entender el eje del desencuentro público entre hombres y mujeres, aireado y pensado en un locus semi-privado y de clase media-alta que son las cenas entre matrimonios, forma de ocio y de convivencia, donde se exhibe una clara conciencia de clase, sobre todo en lo referente a las relaciones de poder dentro de la burguesía.

La comparecencia del personaje de De Córdova en este espacio se presenta como la incorporación del donjuán, ya de manera completamente asumida y legitimada. Su asimilación está normalizada dentro del espacio burgués, donde puede llegar a ser una figura pública, muchas veces atildado como escritor, intelectual, o como personaje que tiene una peculiar defensa de sus ideas. Esta naturalización ejerce sobre los personajes un claro efecto taumatúrgico. Por un lado, supone la consecuente admiración por parte de los hombres; él es entendido como tipo que encarna a la perfección la acción de la masculinidad libre y libertina, al que no consideran un peligro que ponga en riesgo su propio espacio patriarcal, probablemente amparados en la camaradería masculina. Y por otro lado, este donjuán también atesorará el reconocimiento de las mujeres como un claro interlocutor de su deseo, como un personaje que las conoce en su naturaleza más íntima, más allá de su función como esposas y madres. Para las mujeres, este personaje también indica la fascinación que les procura su predisposición para satisfacer su vida sexual fuera del matrimonio, aun y a pesar de los costes de la infidelidad.

La elaboración del donjuanismo de De Córdova en estas películas se organiza, en resumen, en torno a los contenidos evidentes de su significado como tipo, que atesora la mirada de hombres y mujeres, y a los que sirve como mediador; facilita la comunicación entre ellos. Representa el mundo de la seducción, y la pasión que implica esta, y encarna la sabiduría en torno a las mujeres que le dota de un conocimiento que privilegia su relación con ellas y que le convierte en una autoridad para los hombres. Hasta cierto punto, este conocimiento tiene algo de sagrado en el sentido en el que estar en contacto con lo ignoto tiene para esta sociedad, aunque sea un conocimiento entre lo psicológico y social que, precisamente por ser privado, no tiene un interés claramente económico ni directamente racionalista. Esta situación de privilegio deriva, absolutamente en todos los casos, en la soberbia que le caracteriza y que siempre se justifica narrativamente aludiendo a un fracaso, confeso o secreto, del pasado. La mirada irónica pasa a ser una característica que denota una inteligencia emocional primordial pero también una otredad nueva que, en el desarrollo de las tramas de las películas estudiadas, devendrá en absolutamente anormal para las convenciones sociales y su entorno. Ser consecuente con el despliegue de su sutil saber respecto a los demás terminará por provocar el caos y la condenación por parte de todos. Estar 
fuera de la norma implica, en su caso, no acatar unas reglas que, aunque están en pleno proceso de transformación y de reelaboración, no dejan de ser coercitivas y de estar vigentes. Su conocimiento sobre lo artificial del matrimonio y sobre el desconocimiento que de las mujeres tienen los hombres será llevado a un extremo que ponga todo el sistema en peligro; algo que nadie quiere que suceda aunque ninguno crea ya en este mismo sistema.

\section{LAS CLAVES DE LA ADAPTACIÓN TEATRAL}

Todo esto adquiere un muy especial tratamiento en las dos películas en las que se rastreará este modelo de análisis recreado por la construcción del personaje/estrella: Las tres perfectas casadas, una adaptación de la obra homónima de Alejandro Casona, que fue versionada, por primera vez en el cine, por Roberto Gavaldón en 1952. La segunda, Cena de matrimonios, adaptación de la obra homónima de Alfonso Paso, dirigida y producida por Alfonso Balcázar, diez años más tarde, en 1962. Ambas mantienen una estructura de conflicto muy parecida, que permite desplegar las posibilidades para estudiar dos desarrollos distintos, desde el mismo punto de partida, que no deja de ocultar un tema eminentemente reflexivo y social. Esta similitud narrativa resulta idónea para analizar cómo se establecen las recurrencias y se esbozan los topoi, y de este modo, calibrar los límites del conflicto inevitable de la diferencia sexual. En otro orden de cosas, ambas películas responden perfectamente a la idea del mercado internacional hispanoparlante, al adaptar a dos autores teatrales españoles de enorme prestigio en el circuito en español, con un sinfín de representaciones de todo su repertorio, conocidos a ambos lados del Atlántico y con un público siempre probable para acercarse a ver las versiones cinematográficas.

Por tanto, en estas dos obras, el personaje de De Córdova sirve de pivote de autoevaluación de tres matrimonios burgueses, que durante una cena conocen que las esposas comparecientes son o pueden ser infieles. En las dos películas, así como en sus obras teatrales de origen, el personaje masculino que interpreta la estrella mexicana se sitúa en la posición que desencadena la tragedia al obligar al grupo reunido a afrontar la verdad sobre la mentalidad en la que reposa su vida como individuos y como grupo. Se erige como maestro de ceremonias que lleva a cabo, directa o indirectamente, el desarrollo dialéctico que da como resultado el desvelamiento de una verdad oculta para todos, que tiene que ver con la naturaleza artificial y alejada de las convenciones amorosas atribuidas idealmente al matrimonio. Estos seis matrimonios son claros ejemplos de las esferas burguesas española y mexicana, profundamente parecidas en estos textos, en las que se apoya la clase desarrollista y dominante de sus sociedades.
Antes de profundizar en el análisis de los elementos que componen este conflicto conviene apuntar a la procedencia teatral de las películas para contextualizar a sus autores españoles. La naturaleza de las obras de origen es fundamental para comprender el foro desde donde las adaptaciones tratan de configurar un horizonte previo de recepción, pero también de organizar sus contenidos. Si como se viene apuntando, la clave para ampararse en la fama de los autores teatrales es uno de los puntos de producción que diseña la intermedialidad del cine, la constitución de las obras teatrales y su ideología va a definir la posición de este medio de cara a su reconversión en género cinematográfico. Sin duda, lo importante en la incorporación de los dos autores teatrales es ubicarlos en una tradición común que revela cómo, a pesar de sus orígenes políticos distintos, y de la residencia en el exilio de Casona y en la España franquista de Paso, ambos convergen en una aproximación similar para abordar una temática social contemporánea. De alguna manera, en ambos está el planteamiento reconocible que pretende afrontar la modernización como preocupación en sus obras dentro del contexto del teatro comercial de los años cuarenta y cincuenta. La modernización se refleja en la acción de reubicar en sus tramas la mentalidad capitalista como preocupación ideológica fundamental. Se puede decir que estos dos autores sintonizan en su mirada hacia el protagonismo femenino que el nuevo contexto social evidencia. Ya en el periodo que vincula a estas dos décadas, la reflexión sobre la modernización tiene, sin duda, la mirada puesta en la regeneración de los valores en torno a la diferencia de clases y en la vertebración del espacio público basado en ideas democráticas e igualitarias. Sin embargo, ambos coincidirán en una visión abiertamente crítica hacia el papel político de las mujeres en este contexto, que se pone de manifiesto en la elaboración de unas argumentaciones abiertamente revisoras del papel de la mujer e inquisidoras respecto a sus movimientos individualistas o emancipadores. El personaje del mediador permitirá avistar otras lecturas que fortalezcan su acción pública, a pesar de que en el caso de la obra de Casona sea una figura que revisita a Don Juan, que ya tiene siglos de edad, y en el de Paso sea un escritor moralista, absolutamente desencantado. La condición de sátira social de ambas obras teatrales define de antemano el código de lectura por el que se apuesta para entender su exposición abierta de la diferencia sexual.

En esta medida y atendiendo a estos códigos de género, ambas adaptaciones se configuran como un aprovechamiento inteligente de las herramientas narrativas y estilísticas que cine y teatro aportan para la producción de las ideas. Si, como hemos dicho, estas dos películas deben ubicarse en un género exógeno al cine como es la sátira social del ámbito teatral, los elementos que se ponen en juego 
para acomodarlos al sentido cinematográfico serán los propios de la intriga psicológica. ${ }^{8}$ En este sentido, la obra teatral de Casona (no tanto esta obra en concreto) dialoga desde su generación anterior a la Guerra Civil española con el desarrollo psicológico de los personajes desde su propio estilo de naturalizar la otredad: "lo otro" es abordado desde el despliegue de elementos fantásticos o excéntricos, que aportan a la normalidad de la vida de los personajes la sensación de extrañeza que trastoca las convenciones y que habilita un diálogo entre los hombres que busca desembocar, en último término, en la filantropía. En el caso de Paso, su perfil ideológico estará totalmente influido por los autores teatrales más modernizadores de la escena española ${ }^{9}$ pero, sobre todo, por los renovadores norteamericanos, a los que conocerá en las representaciones que hay en España y en sus viajes fuera del país. Paso trabaja específicamente el thriller, que muchos críticos apuntan como lo mejor de su repertorio (Planells, 2005) pero, sobre todo, elabora una inmensa obra que le convierte en el autor por excelencia del teatro comercial de buena parte del franquismo. En este sentido, su trabajo se quiere abiertamente crítico con el mundo en el que se ubica, aunque sea con los convencionalismos que le exige el circuito comercial y las expectativas del público al que constantemente quiere aleccionar. ${ }^{10}$ Aunque se ha afirmado que el efecto será catártico, precisamente el contrario. ${ }^{11}$

\section{LA IDEA CINEMATOGRÁFICA DEL MATRIMONIO PERFECTO}

Probablemente, la producción de estas películas pretendían seguir parámetros internacionales y buscar un público internacional hispanoparlante que reconociera las historias como suyas. En ello, la aportación de estos autores teatrales se tiene que leer como la idoneidad que aportan al ubicar las peripecias en torno a un topos vinculado a la tradición teatral española como es la honra femenina. El estatus del género femenino aportado por la cultura, probablemente, mediterránea sirve para evidenciar las convulsiones que está sufriendo la dialéctica propia de la diferencia sexual precisamente por la puesta en entredicho de este elemento como catalizador social. Resulta imposible no atender a este estilema de nuestra tradición al comprender el corazón del conflicto de ambas obras, en un contexto burgués. Recordemos que su nudo argumental se desencadena tras el conocimiento, por parte de los hombres, de la infidelidad de una de las mujeres. La honra femenina sirve de espoleta para evidenciar el síntoma que pone de manifiesto la crisis de los valores tradicionales en torno al matrimonio, pero también hace visible el miedo identitario y social que implica para los hombres el deseo femenino en libertad. La puesta en escena del conflicto se dispone en estas obras teatrales y cinematográficas en torno a los elementos cruciales que tienen que ver con el locus, en el que se teatraliza el drama, y el topos, en tanto que recurso de la dialéctica que desarrolla la retórica que explicará las razones de todos los personajes en el desvelamiento del trauma que supone la infidelidad. En estos dos sentidos, el personaje de De Córdova tendrá una importancia crucial, activa, y actuará como conductor del diálogo.

Siguiendo esta idea, el locus se ambienta en una cena de celebración de aniversario de matrimonio, motivo simbólico que alude, una vez más, a la institución que ejemplifica la reunión convencional de hombres y mujeres, y el modus vivendi de las personas en torno a unidades sociales tradicionales. Esta cena tiene lugar en una casa donde los anfitriones reciben a los amigos de toda la vida, por tanto, se trata de un espacio semi-privado. Esta posición es clave para la representación de los roles de todos en un ambiente lúdico: se construyen allí de manera crucial las relaciones entre ellos, siempre en torno a constantes también tradicionales en la actuación de la diferencia sexual (la comida auspiciada y controlada por las mujeres, la bebida y el tabaco consumido por los hombres, el baile que reúne a ambos, o el billar que separa a los hombres de las mujeres). Para cercar aún más a los personajes, fuera llueve tormentosamente, de manera que el mundo exterior se hace presente como un espacio hostil, irracional, pero que hace eco del desgarro que tendrá lugar a lo largo de las veladas. La tormenta hace gótico el conflicto y alude a lo siniestro de las pasiones, de la posibilidad de saber con exactitud quién es el otro. La tormenta es también la amenaza del mundo que no es de ellos, ese espacio controlado y de clase en el que se encuentran, también, para reafirmarse.

Es interesante pensar cómo este espacio, planeado como privado pero abiertamente público, hace posible que la proclamación del adulterio se convoque como topos que se esboza como ensayo, como prueba para saber cómo dirimir el resultado del conocimiento de la verdad en el momento en el que sea absolutamente público, conocido y, por tanto, real. La retórica de la dialéctica que se pone en marcha para saber qué hay detrás de la vida realmente privada de las tres mujeres de cada película exhibe una pulsión angustiosa por parte de los hombres que son incapaces de aplicar a sus mujeres la doble moral que ellos mismos han vivido todo el tiempo de casados. En ambas películas, la posibilidad de que la infidelidad sea algo público acciona una neurosis social de la que, precisamente, De Córdova está exento, motivo más para que actúe como moderador de la evolución de la opinión de todos los personajes. Por su parte, las mujeres también admiten claramente la norma de la mentira y son fieles garantes del bienestar y la apariencia que debe existir para disfrutar de la posición social que detentan. Sin embargo, en todos los casos, el 
proceso narrativo que evoluciona hacia el topos de un interrogatorio, en un intento casi policiaco por saber la verdad sobre qué han hecho, o qué han deseado, desvela una trama sentimental que los hombres son incapaces de formular. La insatisfacción, el deseo por lo prohibido, por lo siniestro, por lo oculto, por la aventura, por el amor menos convencional, salen a flote como un tributo que en ambas obras deja asomar el discurso melodramático para construir a los personajes femeninos que, en este tránsito, logran ser absolutamente complejos frente a sus partenaires masculinos.

Por otro lado, esta combinación retórica de generar un espacio para el devaneo filosófico, que da lugar a la pesquisa sobre lo que probablemente ha sucedido, se organiza siguiendo una constante recurrencia a sucesos previos que son recogidos, singularmente en ambas películas, de manera relatada y nunca aludiendo a posibilistas flashbacks. Es interesante este recurso porque de la mano de la palabra como forma narrativa se logra articular el discurso, y también desarrollar los acontecimientos de manera siempre distante, intelectual. Esta es una de las mayores atribuciones de la persona cinematográfica de De Córdova, uno de sus valores más firmes como estrella. La creencia en la palabra no impedirá, de todos modos, dotar a las películas de acercamientos en primer plano a los rostros, y de proclamar una sofisticada puesta en escena al ambientar las casas atiborradas de muebles y aditamentos de claro significante gusto burgués, que el montaje utiliza en interés del desarrollo dramático.

Finalmente, en todos los casos, la composición del trauma solo puede saldarse con la tragedia que implica la muerte de alguno de los personajes, que parece adivinar una operación catártica para los otros y, muy probablemente, para el público de las obras. En esto, toda la pulsión por la verdad, toda la inquisición que ha dirigido el personaje de De Córdova en una acción que busca enjuiciar a las mujeres, y es compartida por todos, denota una interesante perversión racionalista por evidenciar los motivos por los que la hipocresía del mundo de la clase media y su controlada economía de los afectos se resumen en la operación de poner sobre la mesa las heridas de una sociedad en cambio. Es aquí donde las mujeres son las víctimas propiciatorias de una serie de transformaciones en las que ellas mismas son objeto y sujeto de las miradas que lograrán el cambio.

\section{LAS TRES PERFECTAS CASADAS}

El año de producción de esta película es intenso para Arturo de Córdova. Realizará dos películas para la productora Televoz (El rebozo de Soledad y Cuando levanta la niebla), de Miguel Alemán jr., hijo del presidente de la República mexicana, y terminará el año con una comedia para Clasa Films
Mundiales, Fruto prohibido, y con su personaje más conocido en $E l$, de Luis Buñuel (Paranaguá, 2001). Son cinco películas en las que tiene papeles protagonistas o emblemáticos, propias de su lugar en la cinematografía mexicana, como se apuntó más arriba. La versión teatral de Las tres perfectas casadas se había estrenado en el Teatro Avenida de Buenos Aires por la compañía de Lola Membrives, el 18 de abril de 1941. En España, no se verá hasta septiembre de 1965, dirigida por Cayetano Luca de Tena, en el Teatro Lara de Madrid. Años más tarde, esta obra tendría un remake a cargo de Benito Alazraki (Cinematográfica Pelimex, 1971). Según ha estudiado García-Abad García (2010: 286), Casona se basó en un cuento de Arthur Schnitzler, Der Tod des Junggessellen (La muerte del solterón) perfectamente inscrito en la revisión crítica de la cultura burguesa de cambio de siglo, aunque la historia de Casona comenzaba donde la había dejado el autor austriaco.

Las tres perfectas casadas (Roberto Gavaldón, 1952) se inscribe perfectamente dentro de la política de Filmax de realizar un cine de gran producción y tramas asociadas a las clases dirigentes y pudientes. Así los decorados ideados por Jorge Fernández para los estudios San Ángel Inn destacan por la composición grandilocuente y los grandes espacios, mientras que la casa de Gustavo Ferrán, personaje de De Córdova, también tiene unas dimensiones magníficas para un piso de soltero, con un mayordomo (interpretado magistralmente por Arturo Soto Rangel) y una enorme biblioteca. No olvidemos que su personaje es un escritor. La presencia de criados, mayordomos y, sobre todo, el impecable vestuario de las tres mujeres protagonistas, que es señalado por la crítica cinematográfica contemporánea, confirman este ambiente (Anónimo, 1953; Ariel, 1953). El locus aristocrático permite el acercamiento al lujo de los ricos y poderosos para desvirtuar de manera tajante su mundo. Esto lo llevará a cabo uno de los suyos, el propio escritor Gustavo Ferrán, experto en libros sobre la identidad femenina, sobre el matrimonio, vividor, cínico pero testigo de la supuesta felicidad de sus tres amigos del colegio, casados con tres mujeres probas de esta sociedad mexicana.

La película se inicia con la celebración del aniversario de sus tres bodas y con la extraña ausencia del amigo Ferrán, padrino de todas ellas. La velada termina violentamente con la noticia de que ha muerto en el avión que le traía a la cena desde Europa. Este dato, solo conocido por los hombres, lleva a la lectura de una carta que dejó a los tres para ser abierta tras su muerte. En la carta declara haber tenido relaciones sexuales con sus tres esposas. La noticia rompe traumáticamente la admiración que previamente le habían profesado en su recuerdo y activa un proceso de especulación sobre cómo afrontar el hecho que solo Máximo (José Elías Moreno) pone en duda. La búsqueda de una solución para 
que todo este penoso descubrimiento no se sepa, posición defendida por Javier (José María Linares Rivas), contrasta con la reacción violenta de Jorge (René Cardona), que se prepara para una venganza contra su mujer que comience por la liberación de los preceptos censores hacia la salud impuestos por ella y por la destrucción de su mundo pacato. Las mujeres primero desconocerán el hecho y solo se verá la fría reacción de Ada (Laura Hidalgo), esposa de Javier, la verdadera interlocutora de Gustavo, de la que él ha estado enamorado toda su vida, que sabe de la compleja situación que se ha creado con la falsa muerte (Gustavo aparece cuando todos se han marchado y solo quedan los dos anfitriones despiertos) y la existencia de una carta que desvela algún secreto. Más tarde se conocerá la reacción ante la muerte de Gustavo de Leopoldina (Miroslava), esposa de Jorge, piadosa filántropa que reacciona a la noticia de manera histérica.

La construcción de las mujeres en torno a evidentes estereotipos hace referencia al mismísimo cuadro expuesto por Fray Luis de León, en el siglo XVI, en el libro que da nombre a la película, manual de buenas costumbres para la mujer casada (Morant, 2005: 51-57). Así, las tres mujeres son caracterizadas por las ideas que representan: la inteligencia de Ada, el pudor de Genoveva (Consuelo Frank) y la caridad de Leopoldina. Frente a esta santificación de las esposas virtuosas y antes de conocer su infidelidad, se nos ha relatado la rebeldía masculina que ha hecho que esa perfección sea contestada con las infidelidades de Jorge y de Javier; porque, como dice Jorge, "Todo lo perfecto es inhumano" (8 min $45 \mathrm{~s})$. No así de Máximo, representante del amor cortés. Cuando Máximo afirma que estas traiciones podrían ser respondidas por la misma actitud por parte de las mujeres, los otros dos hombres responden con la imposibilidad de que las mujeres tengan esa misma libertad. Estas declaraciones son interesantes porque explicitan con claridad la diferencia entre hombres y mujeres, y se auspicia el argumento en la autoridad del gran experto en el tema, el propio Gustavo Ferrán:

MÁXIMO: Si según ustedes tienen pleno derecho como hombres de engañar a sus mujeres ¿No sería lo lógico que ellas tuvieran el mismo derecho? JORGE: ¿Pero cómo va a ser lo mismo? ¿Estás loco? JAVIER: Tan no es igual, que por eso ellas son mujeres y nosotros somos hombres ¿Verdad? JORGE: ¡Claro! JAVIER: Y si no, que lo diga Ferrán JORGE: Sí, Ferrán, que ha escrito libros famosos sobre el amor y sobre la inferioridad biológica de la mujer. MÁXIMO: Estimo a Ferrán como amigo y nada más. Su literatura es cinismo barato. JORGE: Pero ¿no me negarás que conoce a las mujeres? JAVIER: ¡Que si las conoce! Como que no se ha enamorado nunca: querer es no conocer, es tener una venda en los ojos. MÁXIMO: ¡Tonterías! (10 min $45 \mathrm{~s}$ )
Esta presentación de la trama, que corresponde al primer acto de la obra teatral, exhibe inmediatamente el conflicto al que se enfrentarán hombres y mujeres cuya lógica es, únicamente, dirimir qué postura tomar frente a la respuesta pública y privada de la infidelidad. Es interesante hacer notar que el espacio se hace claustrofóbico, a pesar de los grandes salones de la casa de Ada y Javier, la fuerte tormenta que hay fuera se marcan ya desde el inicio donde un avión que avanza en una tormenta, locus que presidirá toda la noche y será el presagio de todo lo que causará la tragedia de todos. El uso de una música expresionista, debida a Raúl Lavista, resulta sumamente preciso en marcar el clímax de cada nuevo dato. La música hace que el locus ubique diegéticamente la evolución de los estados de ánimo y conciencia que mueven a los personajes.

La comparecencia del donjuán desvelado resulta envuelta en un aura fantástica y sirve para ridiculizar aún más la situación generada por la traición. El personaje llega marcando su pomposo cinismo: "Salud entrañables amigos, matrimonio ideal, mil felicidades con todo el corazón, mi queridísima Ada. Y, tú, viejo, déjame que te abrace. Por fin, comparezco ante este monumento vivo de la dicha conyugal que son ustedes, reproche constante a empedernida e insana soltería. Permítanme brindar por estos dieciocho años en que día con día han ido ustedes acumulando felicidad como laboriosas hormigas ¡Salud!” (31 min). Al saborear el champán, lo compara con la mujer y afirma "Champaña que como mujer es engañosa, embriagadora, voluble. El eterno femenino presente en las efímeras burbujas de una copa. La ilusión que sobrenada un instante para luego desaparecer como una sonrisa de oro. La quimera inalcanzable" (32 min). Ferrán ignora todavía la tormenta que ha desencadenado con su carta.

El segundo acto de la obra pertenece a Ada, que se enfrenta directamente al conflicto. Defiende su inocencia y lucha motivada por demostrar la paternidad clara de su hija que se ha puesto inmediatamente en duda con la carta. También ayuda a Poldina en su episodio de desquicio y le recomienda que viva su pasión en silencio, en la oscuridad de la noche y en el silencio de su cama. Finalmente, concreta una cita con Gustavo para aclarar toda la situación. Ada se hace portavoz de la hipocresía del grupo que Gustavo explica muy bien: "Estáis tan acostumbrados a la hipocresía que, cuando uno se atreve a decir una verdad, sin ningún interés, lo juzgáis monstruoso. Es lo que llamáis cinismo" (72 min). Ada ofrece una salida heroica al donjuán autodestructivo: obrará la mayor operación de gatopardismo que podrá ejercer por el poder que le arroga ser el único y verdadero amor de Gustavo. Ella le obligará a resolver la situación haciendo uso de su siempre comentada pulsión de muerte. Su propuesta es que muera y, como hizo antes, deje una 
carta donde declare que toda su previa confesión fue una operación de su maldad. Así se reordenará el mundo de nuevo. Gustavo accede pues el juego le parece sutil, salvaje y porque la frontalidad de su amor por ella le permitiría hacer un último gesto desinteresado y total. Esta prueba sería la definitiva muestra de su amor incondicional, que ha cimentado en su tremendo discurso intempestivo y crítico.

Se configura así, en el tercer acto final, el encuentro entre los dos en una escena de reproche y de recuerdo del pasado, en el que, efectivamente, se amaron. Es el momento de enfrentamiento donde se descubre en Ada un amor que siempre ha negado, pues lo ha considerado impuro, y que amenazaba su ideal de vida perfecto, la paz de su hogar. En este sentido, también se resitúa el donjuanismo de Gustavo que solo podría haberse salvado de los efectos de su existencial cinismo por la perdición de un amor que le fue negado desde siempre, muy a pesar de esas horas de amor que vivieron muchos años atrás. La muerte accidental en un forcejeo final se cierra con la huida de Ada con la carta, que ella misma deposita en un buzón, cuando deja atrás la casa moderna y hostigada por un viento donde yace Gustavo Ferrán, donjuán definitivamente ajusticiado pero también salvado en un poderoso acto de sacrificio.

La peripecia demuestra, por tanto, que efectivamente las tres mujeres han sido infieles y que la farsa de una felicidad matrimonial burguesa se mantiene eliminando el elemento que ponía en solfa, desde la crítica, desde el escepticismo y desde la propia acción rompedora, ese modelo artificial pero operativo. Sin embargo, la sátira social permanece en toda una trayectoria donde la muerte final es solo un elemento de cierre que hace imposible que los personajes puedan vivir con la conciencia de lo aparente de las relaciones. En esta operación, la masculinidad desubicada que representa el donjuán solo sirve para ser instrumento de los goznes irracionales de un espacio que, a duras penas, puede mantener los principios de funcionamiento de su sociedad atildada y controlada. También es la crisis de los maridos que ya han sabido que sus mujeres pueden buscar su deseo sexual fuera de su mundo doméstico. La mirada expresa y dialéctica de Gustavo ha servido para abrir el discurso y desvelar toda su falsa impronta. Al ser fruto del peligro de esa destructiva posición, tiene que ser obligatoriamente eliminado.

\section{CENA DE MATRIMONIOS}

La última película que realiza Arturo de Córdova en España es un producción de Balcázar PC, una productora nacida precisamente el inicio de la década de los sesenta, que va a tratar de realizar un cine popular que retome historias de interés y que, sobre todo, bascule hacia los subgéneros, como el spaghetti-western, el cine de ambientación exótica, el de terror, y con el avanzar de los años, el cine de destape. Para ello, rentabilizaron sus estudios, situados en Esplugas del Llobregat, y se aseguraron la distribución de su obras a través de la productora Filmax, una de las más potentes con el paso del tiempo y todavía hoy en activo.

De Córdova ya había sido contratado por la productora dos años atrás para protagonizar Hay alguien detrás de la puerta dirigida por el argentino Tulio Demicheli, director en la nómina de la productora, y basada también en una obra de éxito del autor teatral Alfonso Paso. La idea de adaptar a Paso al cine estaba, por tanto, fielmente asentada en la seguridad de un autor de éxito. En el caso de Cena de matrimonios, la obra se había estrenado con la compañía de Alberto Closas (que desempeñó el mismo papel que haría después De Córdova), precisamente otro actor francamente relacionado con América Latina, que estrenó la obra en el Teatro de la Comedia de Madrid, el 16 de octubre de 1959.12 Del elenco que llevó a cabo el estreno teatral, únicamente la actriz Susana Canales, que en el expediente de censura ${ }^{13}$ aparece como argentina, será la única que haga el mismo papel en teatro y cine. La incorporación de De Córdova al proyecto permitía lanzar internacionalmente la película ${ }^{14} \mathrm{y}$ asociar su papel a su propia persona cinematográfica.

El locus de la obra es mucho más claustrofóbico que en Las tres perfectas casadas, aunque posee la misma estructura de una cena de aniversario (esta vez solo de los anfitriones) que reúne a tres matrimonios al que ha de sumarse uno más del que únicamente llega solo el marido, Carlos (Arturo de Córdova), aunque se dilate la espera de su mujer, Adriana, de la que todos sabemos desde el principio que le es infiel con un conocido donjuán llamado Luis Dephillipe (ninguno de los dos aparece en escena). Si en el caso de Las tres perfectas casadas es la música la responsable de identificar con claridad el género y añadir las notas melodramáticas que enfaticen la intriga, aquí estará en la puesta en escena la responsabilidad de una escenografía en torno al salón (y su visión desde la terraza) donde el espacio permite jalonar el movimiento de la cámara entre los personajes que se mueven para hablar entre sí, que merodean para explicarse, que se enfrentan físicamente cuando la confrontación dialéctica es expresa. En esto, se reconoce la labor sutil y efectiva del escenógrafo Juan Alberto. ${ }^{15} \mathrm{Y}$ en segundo lugar, la planificación visual resulta igualmente magnífica y logra mantener el clímax de tensión, sobre todo durante la segunda y tercera parte en la que se desarrollan los interrogatorios a las mujeres sobre sus posibles devaneos. En todo momento se mantienen tres personajes en el plano, en distintas posiciones y en cercanía respecto a la cámara, que permite ubicar a Carlos, que lleva a cabo las incisivas entrevistas, entre las parejas que hablan entre sí a través de su mediación. 
Queda por tanto encuadrada la elaboración del locus cerrado y privado, donde se revelará, de nuevo, la hipotética verdad del adulterio, esta vez a través de dos llamadas anónimas. En este sentido, la trama sigue un discurso totalmente policiaco, pues si una de las llamadas había sido tramada por Julia (María Dolores Pradera) y Laura (Marisa de Leza) para desenmascarar las infidelidades de sus maridos, la segunda resultaba injustificada y hacía conveniente pensar en la posibilidad de que su contenido fuera cierto: "A uno de los maridos de la cena le engaña su mujer". Si pudiera parecer que todo apuntara a la infidelidad de la mujer de Carlos, sabida a voces y que justifica el espíritu cínico, autodestructivo y contestatario de su personaje, precisamente la imposibilidad de hacer de esto un secreto desvelado incita la duda angustiosa de los maridos presentes. Carlos, divertido y borracho, llevará a cabo un interrogatorio, casi exigido por los hombres, que trate de poner a prueba la vida privada de las mujeres, que quizás desvele una intimidad donde, únicamente, sería reseñable encontrar infidelidad. Este agresivo interrogatorio, intimidatorio y procaz, sigue precisamente el título de la película en su estreno en México ¿Qué hacen las mujeres mientras sus maridos trabajan?. De Córdova aparece como un hombre derrotado, exprimido por su dolor pero con un discurso exagerado, hiriente, que dejan ver sus ojos desgarrados, su pelo alborotado por la borrachera y el sudor. Desgraciadamente, fue doblado con lo que perdió la fuerza de su carácter que mantiene en un personaje verboso y dialéctico que el actor mexicano dominaba a la perfección.

Cena de matrimonios parte, por tanto, de esta impronta en la búsqueda de la verdad, que estará legitimada en la puesta en entredicho de las honras de estas mujeres, y solo traerá desconsuelo y humillación para todos. En el relato de esas mismas tardes solitarias vividas por las tres se desvelará su descontento, su sensación de abandono constante y de la futilidad de sus vidas, el desahogo en el consumo y en la construcción exquisita de su belleza social. El modelo narrativo se asienta sobre el eje de cierto thriller policiaco con la incorporación de los cuadros en las que cada mujer desvela sus frustraciones y la imposibilidad de satisfacer su deseo, también el sexual. Esta búsqueda de la verdad revela otra no esperada e incorpora la expresión melodramática que localiza con destreza su configuración como personajes complejos frente a sus maridos, únicamente esquematizados por la búsqueda del lucro personal, del consumismo de electrodomésticos o del elogio de la vida nocturna con otras mujeres en las que se valora su independencia y su apariencia de normalidad a pesar de su "profesión" de queridas.

Frente a todo esto, el personaje de De Córdova establece un diálogo teórico con su rival Dephillipe, que huye esa misma noche con su propia mujer, donde desemboca toda la acritud que le ha aportado su sabiduría en torno al género humano y, más en concreto, de las mujeres. Ya en el primer acto (20 min 20 s) afirma cuando le preguntan si él tiene aventuras: "No hay nada más aburrido que una mujer a la que no se quiere. La mujer es amarga. Lo dice la Biblia. Ese libro que tanto leéis como buenos cristianos ¿Queréis que lea lo que dice de los adúlteros? Es muy sabroso" ${ }^{16}$ El paso desde esa personalidad fruto del engaño, que motiva el adulterio de su esposa, avanza hacia una sensación hacia él de extrañeza y otredad por parte del grupo, que es enormemente intensa. Su tristeza, su enfado agrio y enfático se evidencia en su naturaleza de orador existencialista y mordaz que termina por hacer de su personaje un interlocutor absolutamente intelectual de sus pesares, que extiende hacia toda la sociedad, donde también condena cualquier complicidad con el sistema. Así concreta Carlos ante la afirmación de Antonio (Ángel del Pozo), precisamente el que después se sabrá que es el marido engañado, cuando todavía están solos y hablan sobre cómo tomarse esta llamada condenatoria sobre la posible infidelidad de las esposas:

\footnotetext{
ANTONIO: Yo creo que eso de la honradez a machamartillo es un cuento. Un cuento que nos hemos inventado los hombres para estar tranquilos. Una mujer puede ser honradísima con un hombre mientras pone en ridículo a otro. CARLOS: Bien, me gusta. Basta con pensar que la mujer es un ser humano y no un monstruo sagrado para que le empiecen a temblar las piernas al más pintado. $(25 \mathrm{~min} 15 \mathrm{~s})$
}

Carlos ha sido el primero en sentir ese pánico porque fue precisamente su creencia en la pureza de la mujer la que le había hecho entrar en un espacio de neurosis al saber que su esposa no era virgen cuando se casó. Este es un relato del pasado que se refiere verbalmente y se utiliza para explicar su personalidad autodestructiva e hiriente. Esa pérdida de fe y de rechazo de su mujer hará que aparezca la contrapartida que representa Adriana, fuera de plano y ausente físicamente de la obra teatral, que en el alejamiento de Carlos encuentra su propio deseo sexual que le hará ser abiertamente infiel y terminar siguiendo al donjuán de la obra con el que huye. El deterioro emocional de Carlos ante esta posibilidad anunciada por Adriana en varias ocasiones también le había dejado la huella del trauma, pues Carlos le había suplicado que no le abandonara, tal y como Elisa (Susana Campos) se encarga de contar a todos en el tercer acto de la obra. En este sentido, el personaje de Carlos asume la contrapartida del donjuán, incapaz de comprender a las mujeres pero completamente creyente y dependiente de ellas, lo que vale decir el personaje masculino dispuesto a mantener la dialéctica de la diferencia sexual.

El marco que ofrece el adulterio de la mujer de Carlos le legitima para ser el que pueda ejercer 
de juez frente a las mujeres. Esta dura inquisición también se saldará con la abierta defensa de las mujeres honradas (no así de la adúltera) resaltando su calidad humana. Finalmente, la duda sobre la honestidad de las mujeres se zanja cuando se conoce el adulterio de Elisa, que en la obra sale huyendo cuando desvela su pasión oculta y en la película muere en un accidente de coche inmediatamente después. De nuevo, en el cine se cierra el litigio moral con una muerte que compensa catárticamente el desgaste intelectual y vital de todos sus compañeros en esa noche tormentosa. Sin embargo, Carlos está llamado a verbalizar la hipocresía que rige las vidas de esta sociedad de apariencias: "Bastó una llamada telefónica, bien jugada para que Emilio (Rafael Alonso) supiese que su mujer está harta de esta vida insoportable, su mujer, que es buena y honrada, a la que ha obligado a vivir entre la frivolidad y la tontería. Bastó una llamada telefónica para que Enrique (Enrique Diosdado) descubriera que es injusto y soez con su esposa. Que ella merece mucho más. Que el hogar está tambaleándose, por culpa de él y sólo de él" (57 min $10 \mathrm{~s}$ ).

\section{LA VERDAD COMO MASCARADA}

Frente a estas dos películas se tiene, por tanto, la sensación de que el esquema de sátira social está elaborado sobre la frustración como espectáculo. El finísimo entramado genérico, que vuelve a irrumpir como tema crucial poniendo en la picota la vida amorosa y sexual de las mujeres, aparece como un motivo de escarnio que termina por desvelar los procedimientos sádicos de tener que asimilar una libertad sexual que para los hombres es un derecho y para las mujeres un juego peligroso. La mascarada de estas historias comienza por asentar sobre principios dialécticos y racionales la búsqueda de estos indicios para terminar, en el sempiterno gatopardismo, en el mismo lugar cerrado y aparente del que se partía.

Pero en el transcurso de las historias también se desvanece la posibilidad de creer en la firmeza de esta estructura social, matrimonial y burguesa, que oculta los pliegues por donde se cuela el hálito de la modernización entendida como el ejercicio de la libertad por parte de todos, hombres y mujeres. Y aquí tiene su lugar primordial el mediador masculino, partícipe y testigo inteligente de los límites de toda esta tensión. Desde su perplejidad frente a la institución matrimonial y al desfogue extramarital masculino hasta su conocimiento de la pasión de las mujeres, ejerce como maravilloso maestro de ceremonias en la agresiva y terrible afrenta de romper este mundo anquilosado. Aunque el convencionalismo narrativo le obligue a ser el verdadero garante del amor más puro, menos aturdido por el paso del tiempo, su labor de cínico y también de bufón del sistema social, le permitirá decir la verdad o buscarla en el simple movimiento de hacer algo de justicia social y sentimental. Y, en último término, de proveer a los espectadores de las claves para aproximarse a este circuito de crisis y, probablemente, de catarsis. El trayecto es admonitorio y se arroga la docencia desde el estrado de anunciar la veleidad de una sociedad cuyos valores están sumidos en una crisis, probablemente eterna. El topos desde donde confinarse, a medias entre la conciencia de clase y la identidad de género, solo puede pensarse desde la incertidumbre de los propios sentimientos y del trasfondo de los valores:

Cenemos. Pero por primera vez desde que nos casamos, con algo turbio flotando sobre nosotros. Esta puede ser nuestra gran cena de matrimonios ¿Sabéis? Por un momento temí que todo se quedara solo en un vodevil. Pero alguien ha querido revolverlos. Sembrar el pánico y la inquietud entre nosotros. Se nos ha acabado la paz. $(94 \mathrm{~min})^{17}$

\section{AGRADECIMIENTOS}

Agradezco la inestimable ayuda de Asunción García, compañera del Instituto Cervantes, siempre solícita y eficaz a mis peticiones de documentación, a Yolanda Minerva Campos, que me ayudó con la hemerografía mexicana, a María Mayol con la española, y a Félix Piñuela, que me facilitó la copia de Cena de matrimonios. También debo a Brígida M. Pastor la oportunidad de concretar este artículo.

\section{NOTAS}

1. Según Sassoon (2006: 1233) que analiza el caso inglés: "Algunos iban al cine casi todos los días y muchos acudían tres veces por semana; no obstante un estudio realizado en 1943 (cuando estaba a punto de alcanzarse la cota de máxima asistencia) reveló que había un 30 por 100 de la población que no iba nunca al cine. Las mujeres iban más que los hombres, las clases bajas más que la de los directivos y profesionales, los jóvenes más que los adultos, y los habitantes urbanos más que los del campo".

2. En estos casos, el género en el que se resuelve la trama es la comedia que permite a su personaje acometer el futuro de su madurez con la responsabilidad de forjar una herencia de modernización en esos hijos o justificar su sacrificio "sexual" en pos de la vigorización de las nuevas generaciones.

3. En el análisis que aquí se hace de las posibilidades explicativas del género cinematográfico, se pasa por la inserción en él de personajes desarrollados a través de la estelarización de su actor/persona principal, que siempre proveerá otros significados. En el caso de De Córdova, se abordará la construcción de la diferencia sexual y las lecturas de género desde una perspectiva cultural. Para ello, se utilizan dos conceptos dramáticos y estilísticos, que permiten estructurar los espacios y analizar la función social de sus historias. El locus haría referencia al espacio físico, perfectamente identificado con la clase, el lugar público y el privado, donde las relaciones sociales y de género son conocidas por los personajes y el espectador, y se asocia claramente con el género que los utiliza como recurso de estilo (puesta en escena, fotografía, sonido, montaje). Y por otro lado, el topoi hace referencia a la disposición narrativa dentro del locus que asume, dentro de las constancias y diferencias necesarias de la economía de los géneros, las posibilidades de variación y de devenir 
ideológico del mismo que se sigue a través de la peripecia, y que pueden cambiar de unas películas a otras que pertenezcan a un mismo género. Esto es especialmente interesante para nuestro estudio sobre la confrontación dialéctica de la diferencia sexual. En último término, son precisamente las recurrencias temáticas las que cultural y antropológicamente permiten analizar cómo se construyen las preocupaciones que se relacionan con lo social y lo individual en cada momento, y su tejido en torno a mentalidades que, necesariamente, han de constituir ideologías en liza, aunque sea de manera no explícita.

4. Mi esposa y la otra (1951); Fruto prohibido (Clasa Films Mundiales, 1952) ambas de Alfredo B. Crevenna; Amor en cuatro tiempos (Filmex: Luis Spota, 1954); Mi esposa me comprende (1957), Mis padres se divorcian (1957) ambas para Filmex y dirigidas por Julián Soler; y Hay alguien detrás de la puerta (Producciones Balcázar: Tulio Demicheli, 1960).

5. Su última aventura (Producciones Mercurio, 1946); Cinco rostros de mujer (1946) ambas dirigidas por Gilberto Martínez Solares; Paraíso robado (Clasa Films Mundiales: Julio Bracho, 1951); El valor de vivir (Internacional Cinematográfica: Tito Davison, 1953); La entrega (Filmex: Julián Soler 1953); Feliz año, amor mío (Filmex: Tulio Demicheli, 1955); Canasta de cuentos mexicanos (Jorge Kohn: Julio Bracho, 1955); A media luz los tres (Filmex: Julián Soler, 1957); Isla para dos (Felipe Mier: Tito Davison, 1958); La cigüeña dijo sí (Filmex: Rafael Baledón, 1958); El amor que yo te di (Alfa Films: Tulio Demicheli, 1959).

6. Dios se lo pague (Argentina Sono Films: Luis César Amadori, 1947); Las tres perfectas casadas (Filmex: Roberto Gavaldón, 1952); La herida luminosa (Producciones Balcázar: Tulio Demicheli, 1956); y Cena de matrimonios (Balcázar Producciones Cinematográficas: Alfonso Balcázar, 1962).

7. Alejandro Casona consigue su éxito como autor, ya en el periodo de la Segunda República española. Se exilia viajando con una compañía que recorre América latina para terminar residiendo en Argentina. Aunque Scavuzzo (1993) y Leonardi (2006) han estudiado su presencia en Buenos Aires, él mismo asegura tener una enorme distribución internacional cuando regresa del exilio a España en los años sesenta (http://www.alejandro-casona.com [consultado 17/07/2011]). Por su parte, Alfonso Paso procede del teatro independiente de la primera posguerra para luego asumir los códigos del teatro más comercial de la década de los cincuenta y sesenta. Realiza varios viajes a América latina presumiblemente acompañando a sus obras (Mathias, 1971: 41-46).

8. Por otro lado, y también en complicada combinación entre las relaciones entre la producción teatral y la cinematográfica, es imposible pensar en este cine sin tener en cuenta la evolución del teatro norteamericano desarrollado en los espacios centrales y alternativos de Broadway (Antón Pacheco, 2005) y en su aprovechamiento que tendrá lugar en las adaptaciones cinematográficas de Tennessee Williams, Arthur Miller y Edward Albee. La mirada alternativa y crítica de estos autores llevará a cabo una interesante renovación de la escena y una acerba crítica social a la América de los años cincuenta. Su influencia está, lógicamente, en las adaptaciones que se realizan pero también en la presencia del cine norteamericano que llega de manera más inmediata aportando otros contenidos (Espejo Romero, 1998).

9. Paco de Moya (2003: 179) afirma "La conexión con el teatro de Alejandro Casona, y más aún, con el de Jardiel surge por el planteamiento general de los acontecimientos, disparatados en apariencia, opuestos a lo que se admite como normal".

10. Paso protagonizó el debate sobre la función y el sentido del teatro contemporáneo, que le llevó a publicar el artículo "Los obstáculos para el pacto" en la revista de investigación teatral Primer Acto, 12 enero-febrero de 1960. Era un artículo donde desarrollaba la teoría del pacto con el público, donde defendía que se tenía que contar con el beneplácito del público para no incurrir en rupturismos, aunque se estuvieran tratando de comunicar elementos críticos (desarrollado en Marqueríe, 1960: 48-50). Este artículo fue contestado por Alfonso Sastre, que le tildó de traidor, en su artículo "Teatro imposible y pacto social" en Primer Acto, 14 mayo-junio de 1960. Antonio Buero Vallejo intervino con otro artículo, "Obligada precisión acerca del imposibilismo", Primer Acto, 15 julio-agosto de 1960. Finalmente, Alfonso Sastre volvió a contestar a los dos en "A modo de respuesta" Primer Acto, 16 septiembre-octubre de 1960. Todos estos artículos están recogidos en García Lorenzo (1981).

11. Ruiz Ramón (2005: 427) llama a este ciclo teatral "neorrealismo rosa": "[A]cabada la hábil escenificación de esta crónica escandalosa, la buena conciencia del público burgués, del "querido público" de Paso, sale reforzada por el espectáculo, pues, naturalmente, todos cuantos lo forman se sienten inocentes de tales escándalos que nada tienen que ver con ellos (...) no hay posibilidad de autoidentificación, aunque sí de autocomplacencia por contraste".

12. Alberto Closas adaptaría la obra para la televisión argentina en 1969. También, Mary Delgado la llevó por España con su compañía en 1961, y estuvo tres años en cartel en Barcelona, en el teatro Alexis entre 1960 y 1963.

13. Archivo General de la Administración [AGA]. Cena de matrimonios. Expediente 25846.

14. En México se estrenó como ¿Qué hace su mujer mientras usted trabaja?, la pregunta que desencadena en la obra y la película el juego de los interrogatorios. García Riera (1994: 249) no reconoce la película como mexicana. En el expediente de censura antes citado se informa de que se ceden los derechos de distribución a Gonzalo Elvira, jr. para Argentina, Chile y Uruguay, por un mínimo de 5000 dólares.

15. Según España y Juan i Babot (2005: 36-37): “uno de los pocos méritos de esta cinta es el complejo decorado único, donde Juan Alberto supo solventar con gran habilidad las limitaciones de espacio de los estudios Buch-Sanjuán". Estos eran unos publicistas. Por otro lado, la escenografía de la obra estrenada por la compañía de Closas estuvo a cargo de Santiago Ontañón que realizó un trabajo exquisito que fue también aplaudido por la crítica (Marqueríe, 1959: 79).

16. En la obra teatral se expresa así: "A mí las mujeres me preocupan, me aterran, me duelen, me asombran. Las quiero, las odio. Siento deseos de estrangularlas y de poner su retrato debajo de la almohada. La mujer es amarga y solo puede divertir a un cretino" (Paso, 1963: 33).

17. La obra teatral termina de modo similar: "Cenemos. Pero por primera vez desde que nos casamos, con una extraña llamada a la espalda. Por primera vez en nuestros treinta y tantos años, con algo turbio flotando sobre nosotros. Esta puede ser nuestra gran cena de matrimonios. Temí por un instante que todo se quedara en un vodevil. Pero nosotros no entendemos de vodeviles. Y yo estoy aquí para transformar los vodeviles de nuestra buena sociedad en algo terrible, sin extremos ... sin frases decisivas. Divirtiéndonos, porque vosotros me divertís. Cena fría ... Bebidas iQué estupenda noche! ¿Sabéis por qué? Porque con los tiempos fáciles, la vida fácil y las conciencias fáciles, alguien ha querido revolvernos, sembrar el pánico y la inquietud entre nosotros, por una cosa que no tiene importancia ¡Por fin! ¡Por fin se ha acabado la paz! ¡Y me parece que está empezando la verdad!" (Paso, 1963: 53).

\section{BIBLIOGRAFÍA}

Anónimo (1953) "Las tres perfectas casadas". Redondel, 15 de marzo.

Antón Pacheco, Ana (2005) El teatro en los Estados Unidos: historia crítica. Cuadernos de Langre, San Lorenzo de El Escorial.

Ariel (1953) "Las tres perfectas casadas". Novedades, 15 de marzo.

Bock, Gisela (2001) La mujer en la Historia de Europa. Crítica, Barcelona.

España, Rafael de y Juan i Babot, Salvador (2005) Balcázar Producciones cinematográficas. Más allá de Esplugas City. Universidad de Barcelona, Barcelona. 
Espejo Romero, Ramón (1998) “Who’s afraid of Virginia Wolf? de Edward Albee, en España, y su posterior influencia en el teatro". Reden. Revista española de estudios americanos, 15-16: 111-121. http://hdl.handle.net/10017/5014 [consulta 22/05/2013]

García-Abad García, María Teresa (2010) "El ser como representación en 'Las tres perfectas casadas' de Alejandro Casona/Benito Alazraki”". En Setenta años después: el exilio literario español de 1939, editado por Fernández Insuela, Antonio; Alfonso García, María del Carmen; Martínez-Cachero Rojo, María y Ramos Corrada, Miguel. KRK, Oviedo, pp. 283-302.

García Lorenzo, Luciano (editor), (1981) Documentos sobre el teatro español contemporáneo. SGEL, Madrid.

García Riera, Emilio (1994) Historia documental del cine mexicano. Tomo 11. 1961-1963. Universidad de Guadalajara, Guadalajara.

Leonardi, Yanina Andrea (2006) "El teatro de Alejandro Casona en Buenos Aires". En Dos escenarios: Intercambio teatral entre España y Argentina, editado por Pellettieri, Osvaldo. Cuadernos del GETEA, 15: 89-102.

Marqueríe, Alfredo (1959) "Informaciones teatrales y cinematográficas. En la Comedia se estrenó 'Cena de matrimonios', de Alfonso Paso". ABC, 17 de octubre de 1959: 79. http://hemeroteca.abc.es/nav/Navigate.exe/hemeroteca/ madrid/abc/1959/10/17/079.html [consulta 16/05/2013]

Marqueríe, Alfredo (1960) Alfonso Paso y su teatro. Escelicer, Madrid

Mathias, Julio (1971) Alfonso Paso. EPESA, Madrid.
Morant, Isabel (2005) "Hombres y mujeres en el discurso de los moralistas. Funciones y relaciones". En Historia de las mujeres en España y América latina. Volumen II. El mundo moderno, editado por Ortega, Margarita; Lavrin, Asunción y Pérez Cantó, Pilar. Cátedra, Madrid, pp. 27-61.

Paco de Moya, Mariano de (2003) "El teatro del primer Alfonso Paso". En La comedia española, entre el realismo, la provocación y las nuevas formas (1950-2000): actas del IV y V Congreso Internacional de Historia y Crítica del Teatro de Comedias, editado por Romero Ferrer, Antonio y Cantos Casenave, M. Marieta. Universidad de Cádiz, Cádiz, pp. 171-186.

Paranaguá, Paulo Antonio (2001) Él. Luis Buñuel. Paidós, Barcelona.

Paso, Alfonso (1963) Cena de matrimonios. Escelicer, Madrid.

Planells, J. C. (2005) "El teatro de Alfonso Paso". http:// jcplanells3.wordpress.com/2006/01/11/el-teatro-dealfonso-paso-1/ [consulta 16/mayo/2013]

Ruiz Ramón, Francisco (2005) Historia del teatro español. Siglo $X X$. 8a. ed. Cátedra, Madrid.

Sassoon, Donald (2006) Cultura. El Patrimonio común de los europeos. Crítica, Barcelona.

Scavuzzo, Mariana C. (1993) "Alejandro Casona en la Argentina: Circulación y recepción de su teatro en Buenos Aires". En Actas del III Congreso Argentino de Hispanistas "España en América y América en España", editado por Martínez Cuitiño, Luis; Lois, Elida y Barrenechea, Ana María. Universidad de Buenos Aires, Buenos Aires, pp. 915-22. 